\title{
Obstetric anal sphincter injury by maternal origin and length of residence: a letter
}

\author{
Rinchen Zangmo ${ }^{1}$, Avir Sarkar ${ }^{1}$, Rakhi Rai ${ }^{1}$, and Anshul Kulshreshtha ${ }^{1}$ \\ ${ }^{1}$ All India Institute of Medical Sciences
}

November 16, 2021

Obstetric anal sphincter injury by maternal origin and length of residence: a letter

It gives us great pleasure to read the study entitled "Obstetric anal sphincter injury (OASI) by maternal origin and length of residence: a nation-wide cohort study" by Sorbye and Bains et $\mathrm{al}^{1}$. We appreciate the authors for conducting a large scale multicentric cohort study on this newer aspect of OASI. However, we wish to make certain observations to further help in comprehending the results.

Firstly, the eligibility criteria for the recruitment of participants needs clarification as to why foreign-born women with Norwegian-born parents were excluded from enrolment. Keeping them as a separate group could have been beneficial in assessing whether environmental factors due to migrating out of Norway had an impact on the incidence of OASI. Futhermore, the greater odds of OASI among women with foreign-born partners has to be digested with a pinch of salt. A subgroup analysis comparing the newborn birth weight (NBW) and head circumference (HC) could be instrumental in solving this dilemma. Prior studies by Vik et al from Norway had demonstrated similar outcomes in neonatal survival as well ${ }^{2}$. In the absence of significant difference in NBW and $\mathrm{HC}$, social issues need due consideration. It probably opens up the arena for potential future research in this very field.

The study does mention that the mean $\mathrm{HC}$ of newborns to foreign-born women with OASI did not differ from Norwegian-born counterparts without OASI. But the $\mathrm{p}$ value mentioned alongside in the text is 0.000 , which would amount to high significance. This area needs clarification.

Table 3 has stratified the association between OASI and the length of residence in Norway. We appreciate this robust comparison as this outcome was vital in hypothesizing the impact of environment and lifestyles on the incidence of OASI. But, it is quite strange to note that women who had childbirth before their lawful residence (probably had immigrated recently) had lesser odds of OASI compared to those who had legal residence upto 4 years. Discrete analysis of this subgroup of patients might give us a better comprehension. Another analysis which can be done is to assess whether the place of delivery (government or private setup) was significantly affecting the prevalence of OASI. It can be thought of as an auxiliary outcome. This will ultimately help in addressing the barriers to optimal utilization of resources and will probably stimulate the health care policy to achieve equitable care across the nation.

References:

Sorbye IK, Bains S, Vangen S, Sundby J, Lindskog B, Owe KM. Obstetric anal sphincter injury by maternal origin and length of residence: a nation-wide cohort study. BJOG. 2021 Oct 28. doi: 10.1111/14710528.16985. Epub ahead of print. PMID: 34710268.

Vik ES, Aasheim V, Nilsen RM, Small R, Moster D, Schytt E. Paternal country of origin and adverse neonatal outcomes in births to foreign-born women in Norway: A population-based cohort study. PLoS Med. 2020 Nov;17(11):e1003395. 


\section{Hosted file}

BJOG 3, Title page.docx available at https://authorea.com/users/446479/articles/545691obstetric-anal-sphincter-injury-by-maternal-origin-and-length-of-residence-a-letter 